\title{
Especialização Fisiológica de Puccinia triticina no Brasil em 2002*
}

\author{
Márcia S. Chaves ${ }^{1}$ \& Amarilis L. Barcellos ${ }^{2}$ \\ 1Embrapa Trigo, Cx. Postal 451, CEP 99001-970, Passo Fundo, RS, e-mail: mchaves@cnpt.embrapa.br; \\ ${ }^{2}$ OR Melhoramento de Sementes Ltda., CEP 99050-380, Passo Fundo, RS
}

(Aceito para publicação em 22/08/2005)

Autor para correspondência: Márcia Soares Chaves

CHAVES, M.S. \& BARCELLOS, A.L. Especialização fisiológica de Puccinia triticina no Brasil em 2002. Fitopatologia Brasileira 31:057-062. 2006.

\section{RESUMO}

A ferrugem da folha é uma das principais doenças que afetam a cultura do trigo (Triticum aestivum). Nas regiões tritícolas da Argentina, Brasil, Paraguai, Uruguai e Bolívia têm ocorrido todos os anos epidemias da moléstia, as quais podem ocasionar perdas de até 50\% no rendimento de grãos de cultivares suscetíveis, se não for efetuado controle com fungicidas. No Chile, a importância da moléstia tem aumentado, especialmente em cultivares de trigo de inverno. Na maior parte dessa região o patógeno está presente durante todos os meses do ano, o que favorece o surgimento precoce da moléstia, o desenvolvimento de epidemias, e a seleção e fixação de novas raças, sendo freqüente a superação da resistência em cultivares comerciais. O objetivo deste trabalho foi identificar as raças do fungo causador da ferrugem da folha do trigo que ocorreram no Brasil durante a safra de 2002 e determinar sua freqüência, distribuição geográfica e alterações de virulência. Foram identificadas 38 combinações de virulência, agrupadas em 12 raças distintas, de acordo com o sistema brasileiro. Esse conjunto representa um grande espectro de virulência, abrangendo todos os genes da série diferencial, embora a Lr16 e Lr21 a virulência tenha se expressado em nível intermediário. Duas novas combinações de virulência foram identificadas, as quais correspondem, respectivamente, aos códigos SPJ-RS e MFT-CT/MFT-HT, de acordo com o sistema norte-americano de nomenclatura. O gene $\operatorname{Lr} 19$ ainda continua efetivo para resistência a todas as raças, assim como as combinações de genes (Lr3+Lr9), (Lr9+Lr16), (Lr9+Lr3ka), (Lr9+Lr21), $(\operatorname{Lr} 16+L r 24)$.

Palavras-chave adicionais: ferrugem da folha, Triticum aestivum, virulência, raças.

\begin{abstract}
Physiologic specialization of Puccinia triticina in Brazil in 2002

Leaf rust is one of the main diseases of wheat (Triticum aestivum). In Argentina, Brazil, Paraguay, Uruguay and Bolivia epidemics occur every year, that can cause yield losses up to $50 \%$ in susceptible cultivars, if fungicides are not used. In Chile, the importance of the disease is increasing, especially in winter wheat cultivars. In most areas of these regions, the pathogen is present all year, favoring the early appearance of the disease, the development of epidemics, and the selection and establishment of new races. Also, resistance breakdown in commercial cultivars is frequent. The objective of this work was to identify the races of wheat leaf rust fungus that occurred in Brazil in 2002, and to determine their frequency, geographical distribution and changes in virulence. Thirty-eight virulence combinations were identified, grouped in 12 different races, according to the Brazilian system. These races represent a wide virulence spectrum, attacking all the resistance genes of the differential series, although at an intermediate level of virulence to $\operatorname{Lr} 16$ and $\operatorname{Lr} 21$. Two new virulence combinations were identified, which correspond, respectively, to SPJ-RS and MFT-CT/MFT-HT, according to the North American system of nomenclature. Despite the new types of virulence, the gene $L r 19$, and the combinations of genes ( $L r 3+L r 9),(L r 9+L r 16)$, $(L r 9+L r 3 k a),(L r 9+L r 21)$, $(L r 16+L r 24)$, continued to be effective for resistance.
\end{abstract}

Additional keywords: leaf rust, Triticum aestivum, virulence, races.

\section{INTRODUÇÃO}

A ferrugem da folha, causada por Puccinia triticina Erikss. (=Puccinia recondita Rob. ex Desm. f. sp. tritici) é uma das principais doenças que afetam a cultura do trigo (Triticum aestivum L.) e ocorre em praticamente todas as regiões do mundo onde o cereal é cultivado. As perdas em rendimento dependem do estádio da planta em que a

\footnotetext{
*Trabalho realizado com o apoio financeiro do Centro Internacional de Mejoramento de Maíz y Trigo (CIMMYT) e do US Department of Agriculture (USDA).
}

moléstia ocorre e, principalmente, da severidade, a qual é função da suscetibilidade da cultivar, da virulência da raça fisiológica e das condições de ambiente (Roelfs et al., 1992).

Na América do Sul, existem duas unidades epidemiológicas, separadas pela Cordilheira dos Andes. A unidade Leste compreende a Argentina, o Brasil, o Paraguai, o Uruguai e as planícies da Bolívia. A unidade Oeste compreende o Chile. Nas regiões tritícolas desses países têm ocorrido todos os anos epidemias de ferrugem da folha, as quais freqüentemente são severas e ocasionam 
perdas no rendimento de grãos de até 50\% em cultivares suscetíveis, se não for efetuado controle com fungicidas (Reis et al., 1996; Annone \& Nisi, 2003; Chaves \& Barcellos, 2003; Viedma, 2003; German, 2003). No Chile, a importância da ferrugem da folha tem aumentado nos últimos ciclos de cultivo, especialmente em cultivares de inverno, onde foram verificadas significativas perdas em rendimento (Madariaga \& Mellado, 2003).

Os países do Cone Sul da América do Sul compartilham de algumas características que predispõem a pouca durabilidade da resistência genética e ao aumento da necessidade de controle químico: as condições de ambiente são extremamente favoráveis, há a presença de plantas de trigo voluntárias nas entressafras, áreas extensas são cultivadas com os mesmos genótipos, pratica-se o cultivo de genótipos suscetíveis, as raças predominantes têm grande semelhança genética e as épocas de cultivo são subseqüentes, formando uma "ponte verde". Esses fatores contribuem para que o patógeno esteja presente na maior parte da região durante todos os meses do ano, favorecem o surgimento precoce da moléstia e o desenvolvimento de epidemias. Como resultado, durante todo o ano há uma grande quantidade de inóculo disponível, o que induz à seleção e fixação de isolados com novas combinações de virulência (Barcellos \& Chaves, 2003a). Além disso, o agente causal da ferrugem da folha do trigo apresenta uma grande habilidade em superar genes de resistência específicos, estejam eles isolados ou em combinações de dois ou poucos genes, havendo atualmente virulência para a maioria dos genes $L r$ mundialmente conhecidos (Singh et al., 2002). Esta habilidade pode ser entendida como o resultado da coevolução entre ferrugens e plantas. Sendo parasitas obrigatórios, estes patógenos coevoluíram com seus hospedeiros como componentes de um sistema muito influenciado pelas condições ecológicas, ou seja, qualquer mudança na população predominante do hospedeiro, resulta em mudanças subseqüentes na população do patógeno, para que o equilíbrio seja restabelecido (Wahl et al., 1984; Barbieri \& Carvalho, 2001).

Neste cenário, é essencial o conhecimento de quais combinações de virulência existem na população do patógeno através do levantamento sistemático de raças. Através deste estudo poderão ser conhecidas prevalências, flutuações, ocorrência de novas combinações gênicas de virulência (novas raças) e efetividade de genes de resistência em uso e ainda não incorporados amplamente em cultivares. Vários países como Estados Unidos, Canadá, Uruguai, Argentina, Austrália, México e Brasil, entre outros, têm feito importantes trabalhos de levantamento de raças de P. triticina. Estas informações têm sido especialmente importantes para dar suporte à tomada de decisões em programas de melhoramento e controle integrado, no que se refere à indicação de genótipos a serem cultivados, à escolha dos genes a serem combinados nos cruzamentos, à escolha da estratégia de utilização da resistência incorporada e à indicação da necessidade ou não do uso de fungicidas.

A Embrapa Trigo prepara anualmente, desde 1988, uma coleção de genótipos de trigo para avaliação e coleta de ferrugens, a qual é enviada a colaboradores de instituições de pesquisa situadas em várias regiões do Brasil e de outros países da América do Sul, a fim de amostrar a população de $P$. triticina de forma abrangente e representativa. Amostras de ferrugem de áreas experimentais e lavouras também são enviadas espontaneamente à Embrapa Trigo para identificação de raças por pesquisadores e produtores.

O objetivo deste trabalho foi identificar as raças do fungo causador da ferrugem da folha do trigo que ocorreram no Brasil durante a safra de 2002 e determinar sua freqüência, distribuição geográfica e alterações de virulência.

\section{MATERIAL E MÉTODOS}

Em 2002 foi preparada na Embrapa Trigo, Passo Fundo, RS, a $15^{\text {a }}$ Coleção para Avaliação e Coleta de Ferrugens do Trigo, composta por 143 genótipos de trigo com genes $L r$ conhecidos para resistência à ferrugem da folha do tipo específica à raça e do tipo "progresso lento" (slow rusting); genótipos de trigo resistentes à ferrugem, linhas isogênicas diferenciais de raças, cultivares indicadas para cultivo, genótipos de trigo duro (Triticum durum Desf.) e testemunha suscetível. Essa coleção foi instalada em 19 locais no Brasil, com a colaboração de outros centros de pesquisa.

Os genótipos foram semeados em parcelas de duas linhas de $1 \mathrm{~m}$ espaçadas por $0,20 \mathrm{~m}$, e com espaçamento entre parcelas de $0,40 \mathrm{~m}$. A cada dez genótipos e ao redor do ensaio foi semeada a cultivar suscetível Morocco. O desenvolvimento das plantas foi acompanhado, sendo efetuados os tratos culturais recomendados para a cultura do trigo. Após o surgimento das primeiras pústulas de ferrugem da folha, amostras de folhas com sinais do patógeno foram coletadas ao acaso e colocadas em envelopes de papel identificados com o número da linha da coleção, local e data de coleta. Os envelopes foram deixados separados um do outro em temperatura ambiente, sem exposição direta à luz solar, por aproximadamente um dia, sendo enviados após este período à Embrapa Trigo para identificação da raça presente em cada amostra. Além do material procedente da $15^{a}$ Coleção para Avaliação e Coleta de Ferrugens do Trigo, amostras de trigo e espécies afins, coletadas em campos experimentais e lavouras comerciais por pesquisadores e produtores, foram também enviadas à Embrapa Trigo.

A identificação das raças iniciou-se ainda em 2002, logo após o recebimento das primeiras amostras e foi concluída em 2003. Para essa identificação, foram feitos isolamentos monopustulares de cada amostra e posterior multiplicação do inóculo na cultivar suscetível Coxilha. O inóculo multiplicado foi inoculado na primeira folha de 
plântulas de linhas isogênicas, de acordo com o sistema norte-americano de hospedeiros diferenciais, para identificação de raças de P. triticina (Long \& Kolmer, 1989), com dois grupos adicionais de genes de resistência $L r$, compondo uma série diferencial com cinco grupos de quatro genes. $\mathrm{O} 4^{\circ}$ e $5^{\circ}$ grupos (adicionais) foram compostos por $L r 10, L r 18, L r 21$ e $L r 23$; e $L r 14 a, L r 14 b$, Lr26 na cultivar Alondra e Lr20, respectivamente. Após a inoculação as plântulas ficaram em câmara úmida e escura por 18 h, e, após este período, foram transferidas para casa de vegetação com condições semi-controladas de temperatura (18-25 ${ }^{\circ} \mathrm{C}$ ) e luminosidade (iluminação natural com suplementação de lâmpadas fluorescentes). Decorridos 15 dias da inoculação, procedeu-se à leitura da reação nas séries diferenciais a cada raça, conforme a metodologia descrita por Roelfs et al., 1992. Foram considerados resistentes as plântulas que desenvolveram tipos de infecção de 0 a 2++ e suscetíveis aquelas com tipos de infecção 3 e suas variações para mais ou para menos. As raças foram identificadas pelo código Prt descrito no Sistema Norte-Americano de Nomenclatura para $P$. recondita f. sp. tritici proposto por Long \& Kolmer (1989). Alguns genes da série diferencial apresentam reação variável conforme a temperatura, portanto, às vezes a mesma raça apresenta variações no código Prt. Para cada raça detectada, juntamente com suas variantes, foi também atribuída a nomenclatura usada no Brasil, na qual a raça é nomeada pela letra “B” (de Brasil) seguida por um número que representa a ordem de surgimento e identificação da raça no Brasil (ex.: B34 - 34 ${ }^{\mathrm{a}}$ raça de $P$. triticina identificada no Brasil pelo sistema Norte-Americano). Este sistema de nomenclatura é informal e apenas identifica numericamente a raça em relação às demais.

No campo, os genótipos também foram avaliados quanto à severidade na folha bandeira (\% de área foliar afetada), usando-se a escala de Cobb modificada (Peterson et al., 1948) e quanto ao tipo de infecção, os quais foram combinados em um único valor chamado de Coeficiente de Infecção (C. I.), conforme Roelfs et al. (1992). Foi calculado o C. I. para cada genótipo em cada local e o C. I. médio de cada genótipo (média dos locais).

\section{RESULTADOS E DISCUSSÃO}

Em 2002, a ferrugem da folha do trigo ocorreu de forma generalizada nas regiões produtoras do Sul e Sudeste do país, tendo sido registrada alta severidade em cultivares suscetíveis, que tiveram até $80 \%$ da área foliar afetada. A Embrapa Trigo recebeu amostras de folhas com ferrugem provenientes do Rio Grande do Sul, Santa Catarina, Paraná, São Paulo e Minas Gerais. Das amostras recebidas, 183 foram identificadas, as quais corresponderam a 38 combinações de virulência, agrupadas em doze raças distintas (Tabela 1). As raças que ocorreram com maior freqüência foram B48 (40,98\%), B40 (12,57\%) e B34 (12,02\%) e as menos freqüentes foram B29 e B35 (0,55\%).
No Paraná, Rio Grande do Sul e São Paulo houve prevalência da raça B48. Em Santa Catarina, o único isolado identificado correspondeu à raça B51 e, em Minas Gerais, foi identificada a ocorrência de três isolados de B34, um de B43 e um de B48 (Tabela 2).

As raças B50 e B51 representam novas combinações de virulência (Tabela 1) e foram identificadas pela primeira vez em 2002, ocorrendo com freqüências de 4,92\% e $7,65 \%$, respectivamente (Tabela 2). A raça B50 é avirulenta aos genes $L r 3, L r 3 k a, L r 16, L r 20, L r 21$ e $L r 30$, e virulenta a $\operatorname{Lr} 1, \operatorname{Lr} 2 a, L r 2 c, L r 9, L r 10, L r 11, L r 14 a, L r 14 b, L r 17$, Lr18, Lr23, Lr24, Lr26 e Alondra. A raça B51 é avirulenta a $L r 2 a, L r 2 c, L r 9, L r 10, L r 16$, (Lr18) e Lr21, e virulenta a Lr1, Lr3, Lr3ka, Lr11, Lr14a, Lr14b, Lr17, Lr20, Lr23, Lr24, Lr26, Lr30 e Alondra. O gene Lr18 pode conferir reação variável a B51 (resistência ou suscetibilidade), dependendo das condições de ambiente, sendo convencionalmente escrito entre parênteses. Estas combinações de avirulência/virulência correspondem respectivamente aos códigos SPJ-RS e MFT-CT/MFT-HT, de acordo com o sistema norte-americano de nomenclatura (Tabela 1). A raça B50 foi isolada a partir de amostras das linhagens PF 950136 e ORL 010808, e das cultivares IPR 87, BRS 221, CEP 27, Avante e IPR 84; e B51, das linhagens PF 970151, ORL 98204, ORL 99535, ORL 98231, ORL 99006, e das cultivares OR 1, CD 104 e Jaspe.

O isolamento de B50 em IPR 84 chamou a atenção por ser esta cultivar, até então, resistente a todas as raças de $P$. triticina identificadas no Brasil. Após obter-se isolados puros de B50, novas inoculações foram realizadas sobre IPR 84, constatando-se que a mesma era resistente a B50. Inferiu-se, portanto, que a amostra coletada pode ter sido proveniente de uma planta suscetível misturada acidentalmente na parcela ou que foram amostradas pústulas de resistência, com os tipos de infecção 1 ou 2 descritos por Roelfs et al. (1992). Assim, IPR 84 continua resistente a todas as raças de $P$. triticina. Também continua efetivo à ferrugem da folha o gene $\operatorname{Lr} 19$ e as combinações de genes (Lr3 + Lr9), (Lr9 + Lr16), $(\operatorname{Lr} 9+L r 3 k a),(L r 9+$ Lr21), (Lr16 + Lr24). A linhagem ORL 98204 (cv. Safira) também é resistente à raça B51.

As raças mais freqüentes em 2002, B48 e B40, e as novas raças B50 e B51 estão entre aquelas com maior espectro de virulência. Conforme dados de levantamentos anteriores (Barcellos \& Chaves, 2003b), as duas primeiras raças citadas também ocorreram em maior freqüência de 1999 a 2001. O número de combinações de virulência que ocorreram em 2002 (23 combinações em 183 isolados) é semelhante proporcionalmente ao encontrado nos levantamentos de 2000 (34 combinações em 273 isolados) e de 2001 (27 combinações em 208 isolados), considerandose o sistema norte-americano de diferenciais $(\operatorname{Lr} 1, \operatorname{Lr} 2 a$, Lr2c, Lr3, Lr3ka, Lr9, Lr11, Lr16, Lr17, Lr24, Lr26 e Lr30). O surgimento de duas novas raças segue o padrão que vem sendo observado nos levantamentos dos últimos cinco anos, que é de zero a duas novas raças/ano. 
TABELA 1 - Nomenclatura brasileira e norte-americana, fórmulas de avirulência/virulência e número de isolados de raças de Puccinia triticina identificadas em amostras de trigo (Triticum aestivum) e espécies afins coletadas no Brasil em 2002. Embrapa Trigo

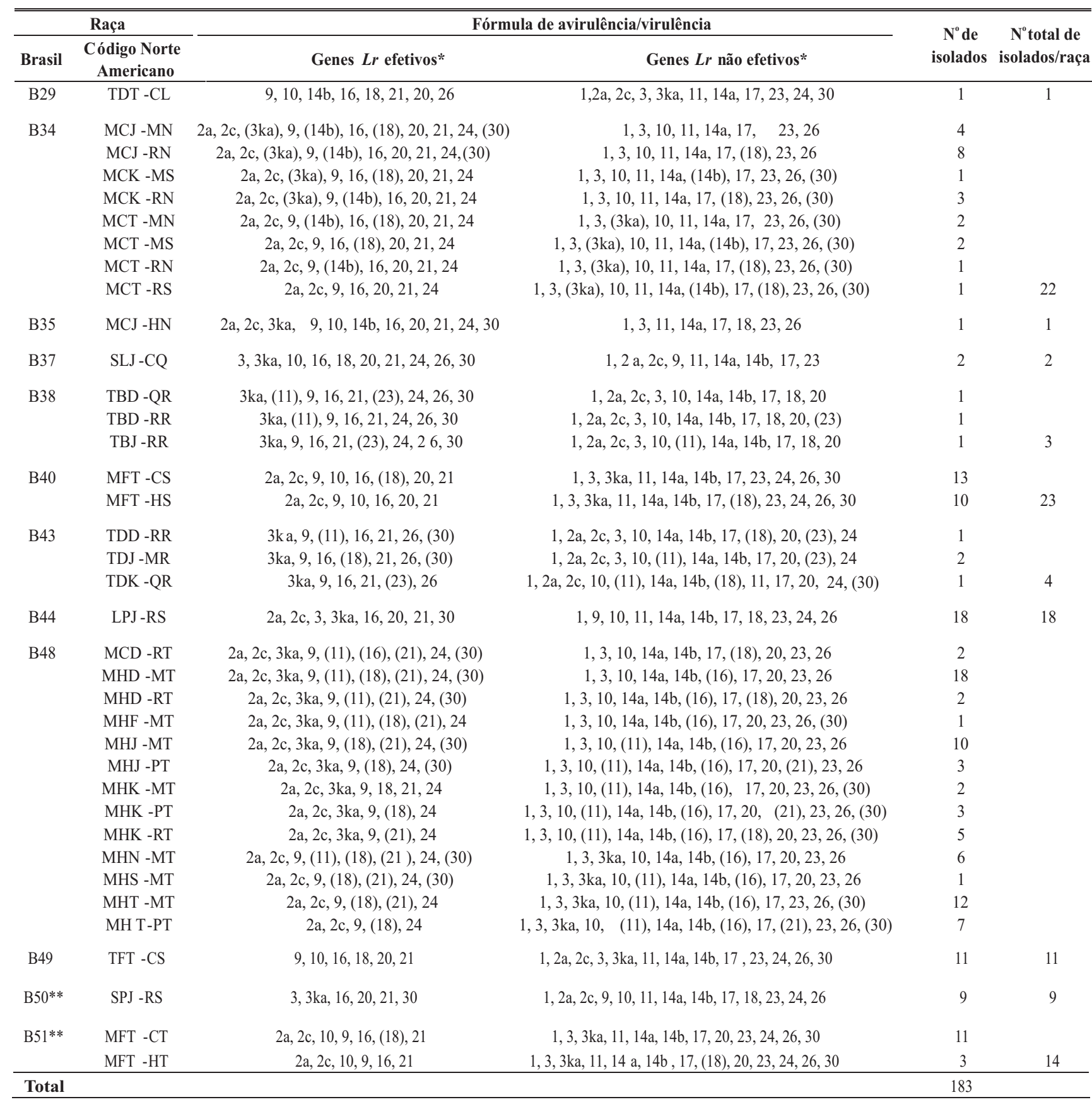

*Genes entre parênteses apresentam sensibilidade à temperatura e podem conferir reação variável (resistência ou suscetibilidade);

**Raças identificadas pela primeira vez em 2002.

O conjunto de raças em 2002 representa um grande espectro de virulência, abrangendo todos os genes da série diferencial, embora a virulência tenha-se expressado em nível intermediário a $\operatorname{Lr} 16$ e $\operatorname{Lr21}$. Todos os isolados identificados foram virulentos aos genes $\operatorname{Lr} 1, \operatorname{Lr} 14 a, \operatorname{Lr} 17$ e $L r 21$, indicando a não efetividade para resistência destes genes à população patogênica de 2002. Também foi observado alto percentual de isolados virulentos aos genes $L r 3, L r 10, L r 11, L r 14 b, L r 23$ e $L r 26$. O mais baixo percentual de virulência foi verificado em $L r 21$, sendo que nenhum isolado foi totalmente virulento, conforme a reação da diferencial. Poucos isolados foram virulentos a $L r 2 a$, Lr2c e Lr9 (Tabela 3). Foram observadas algumas alterações em virulência em relação aos dados de três anos 
TABELA 2 - Distribuição geográfica e freqüência de ocorrência de raças de Puccinia triticina identificadas em amostras de trigo (Triticum aestivum) e espécies afins coletadas no Brasil em 2002. Embrapa Trigo

\begin{tabular}{lccccccr}
\hline $\begin{array}{l}\text { Raça B de } \\
\begin{array}{l}\text { Puccinia } \\
\text { triticina }\end{array}\end{array}$ & RS & SC & PR & SP & MG & Total & \% \\
\cline { 1 - 5 } B29 & 0 & 0 & 1 & 0 & 0 & 1 & 0,55 \\
B34 & 8 & 0 & 11 & 0 & 3 & 22 & 12,02 \\
B35 & 1 & 0 & 0 & 0 & 0 & 1 & 0,55 \\
B37 & 2 & 0 & 0 & 0 & 0 & 2 & 1,09 \\
B38 & 1 & 0 & 1 & 1 & 0 & 3 & 1,64 \\
B40 & 4 & 0 & 18 & 1 & 0 & 23 & 12,57 \\
B43 & 1 & 0 & 2 & 0 & 1 & 4 & 2,19 \\
B44 & 7 & 0 & 9 & 2 & 0 & 18 & 9,84 \\
B48 & 19 & 0 & 45 & 10 & 1 & 75 & 40,98 \\
B49 & 4 & 0 & 7 & 0 & 0 & 11 & 6,01 \\
B50* & 7 & 0 & 2 & 0 & 0 & 9 & 4,92 \\
B51* & 0 & 1 & 13 & 0 & 0 & 14 & 7,65 \\
\hline Total & 54 & 1 & 109 & 14 & 5 & 183 & \\
\hline \% & 29,51 & 0,55 & 59,56 & 7,65 & 2,73 & & 100 \\
\hline
\end{tabular}

*Raças identificadas pela primeira vez em 2002.
1983, citados por Long \& Kolmer, 1989).

Evidenciou-se no presente trabalho a alta diversidade e plasticidade da população de $P$. triticina amostrada no Brasil, assim como a sua grande capacidade de adaptação a este ambiente e às cultivares de trigo com resistência baseada em genes isolados. O número reduzido de genes de resistência ainda efetivos torna cada vez mais difícil o controle através desta estratégia, pois limita os programas de melhoramento a uma base genética para resistência muito estreita, o que tende a tornar a resistência efêmera. Além disso, se uma cultivar for resistente à maioria das raças, mas suscetível a apenas uma delas, haverá o risco de ocorrer uma epidemia, e com isso, aumentam também as probabilidades de maior utilização de fungicidas e de substituição da cultivar. A pesquisa e utilização de formas de resistência mais estáveis, como a resistência parcial de planta adulta (RPA) é uma necessidade cada vez mais urgente. Este tipo de resistência é a alternativa mais promissora para integrar estratégias de controle, uma vez que não causa a intensa pressão de seleção para raças virulentas do patógeno, como ocorre com a resistência específica a raças, baseada em genes isolados.

TABELA 3 - Virulência das raças de Puccinia triticina identificadas em amostras de trigo (Triticum aestivum) e espécies afins em 2002, aos genes $L r$ de resistência da série diferencial. Embrapa Trigo

\begin{tabular}{|c|c|c|c|c|c|c|c|c|c|c|c|c|c|c|c|c|c|c|c|}
\hline & \multicolumn{19}{|c|}{ Genes $\boldsymbol{L r}$} \\
\hline & 1 & $2 a$ & $2 c$ & 3 & 9 & 16 & 24 & 26 & $3 k a$ & 11 & 17 & 30 & 10 & 18 & 21 & 23 & $14 a$ & $14 b$ & 20 \\
\hline $\mathrm{N}^{\circ}$ de isolados virulentos & 183 & 30 & 30 & 154 & 29 & 73 & 80 & 173 & 84 & 151 & 183 & 93 & 131 & 71 & 13 & 180 & 183 & 163 & 96 \\
\hline \% Virulência & 100 & 16,4 & 16,4 & 84,2 & 15,8 & 39,9 & 43,7 & 94,5 & 45,9 & 82,5 & 100 & 50,8 & 71,6 & 38,8 & 7,1 & 98,4 & 100 & 89,1 & 52,5 \\
\hline
\end{tabular}

anteriores (Barcellos \& Chaves, 2003b). Embora Lr21 tenha sido o gene mais eficiente para resistência, houve aumento no percentual de isolados com nível intermediário de virulência a ele. Houve aumento também em percentagem de isolados virulentos a $L r 2 a, L r 2 c, L r 9, L r 16$, $L r 18$ e $L r 20$ e decréscimo a $L r 3, L r 3 k a$ e $L r 30$.

Os dados do C.I. médio, os quais representam a reação a campo dos genótipos da coleção (dados não apresentados), refletem algumas das alterações em virulência observadas. As linhas isogênicas portadoras dos genes aos quais verificou-se aumento em virulência através da amostragem de isolados apresentaram em 2002 valores mais elevados de C. I. em relação à média dos anos anteriores (Barcellos \& Kohli, 2003). Em relação aos genes aos quais foi observado decréscimo em virulência, somente para $L r 3$ houve também decréscimo no C. I., sendo que, para os demais, os dados de campo não expressam a diminuição de isolados virulentos. Lr3ka e $L r 30$ são comumente usados em levantamentos de virulência, mas são difíceis de avaliar devido a sensibilidade à temperatura (Dyck \& Johnson,

\section{AGRADECIMENTOS}

As autoras agradecem ao Dr. M. M. Kohli (CIMMYT) pelo apoio dado à realização deste trabalho e aos pesquisadores da COODETEC, Embrapa Soja, Embrapa Trigo, Instituto Biológico, Instituto Agronômico, IAPAR, OR Melhoramento de Sementes Ltda., Fundação Pró-Sementes, Universidade Federal de Viçosa, Fundação ABC, Embrapa Clima Temperado e EPAGRI pela valiosa colaboração na coleta e envio de amostras de ferrugem da folha do trigo.

\section{REFERÊNCIAS BIBLIOGRÁFICAS}

ANNONE, J.G. \& NISI, J. Situación de las royas del trigo en Argentina. In: Seminario Internacional Resistencia a Royas en Trigo, 2003, La Estanzuela. Seminario Internacional Resistencia a Royas en Trigo - Resumenes. La Estanzuela: INIA, 2003. p.1. BARBIERI, R.L. \& CARVALHO, F.I.F. Coevolução de plantas e 
fungos patogênicos. Revista Brasileira de Agrociência 7:79-161. 2001.

BARCELLOS, A. L. \& CHAVES, M.S. Epidemias de ferrugem da folha em cultivares brasileiras de trigo - Alterações na população do patógeno de 1993 a 2002. In: Seminario Internacional Resistencia a Royas en Trigo, 2003, La Estanzuela. Seminario Internacional Resistencia a Royas en Trigo - III Resumenes. La Estanzuela: INIA, 2003a. p.13.

BARCELLOS, A.L. \& CHAVES, M.S. Epidemias de ferrugem da folha em cultivares brasileiras de trigo - Alterações na população do patógeno de 1993 a 2002. In: Seminario Internacional Resistencia a Royas en Trigo, 2003, La Estanzuela. Seminario Internacional Resistencia a Royas en Trigo - VIII Presentaciones. La Estanzuela: INIA. CD ROM 2003b.

BARCELLOS, A.L. \& KOHLI, M.M. Resultados da XI ${ }^{\mathrm{a}}, \mathrm{XII}^{\mathrm{a}}$, XIII ${ }^{a}$ e XIV ${ }^{a}$ coleção para avaliação e coleta de ferrugem do colmo e ferrugem da folha do trigo 1998/2001. Passo Fundo:Embrapa Trigo/CIMMYT. 2003

CHAVES, M.S. \& BARCELLOS, A. L. Situação das ferrugens do trigo no Brasil e comportamento das cultivares comerciais em 2000, 2001 e 2002. In: Seminario Internacional Resistencia a Royas en Trigo, 2003, La Estanzuela. Seminario Internacional Resistencia a Royas en Trigo - Resumenes. La Estanzuela: INIA, 2003. p.2.

GERMAN, S. Situación de las royas del trigo en Uruguay y comportamiento de cultivares comerciales. In: Seminario Internacional Resistencia a Royas en Trigo, 2003, La Estanzuela. Seminario Internacional Resistencia a Royas en Trigo Resumenes. La Estanzuela: INIA, 2003. p.5.

LONG, D.L. \& KOLMER, J.A. A North American system of nomenclature for Puccinia recondita f. sp. tritici. Phythopathology 79:525-529. 1989.
MADARIAGA. R.B. \& MELLADO, M.Z. Resistencia a royas en trigo. Informe de Chile. In: Seminario Internacional Resistencia a Royas en Trigo, 2003, La Estanzuela. Seminario Internacional Resistencia a Royas en Trigo - Resumenes. La Estanzuela: INIA, 2003. p.3.

PETERSON, R.F., CAMPBELL, A.B. \& HANNAH, A.E. A diagramatic scale for estimating rust intensity of leaves and stem of cereals. Canadian Journal of Research, Section C 26:496-500. 1948.

REIS, E.M., CASA, R.T. \& FORCELINI, C.A. Relação entre a severidade e a incidência da ferrugem da folha do trigo, causada por Puccinia recondita f. sp. tritici. Fitopatologia Brasileira 21:369-372. 1996.

ROELFS. A. P., SINGH, R. P. \& SAARI, E. E. Rust Diseases of Wheat: Concepts and methods of disease management. Mexico, D. F.: CIMMYT. 1992.

SINGH, R.P., HUERTA-SPINO, J. \& ROELFS, A.P. The wheat rusts. In: Bread wheat: Improvement and production. Curtis, B.C., Rajaram, S. \& Macpherson, G.H. (Eds.). FAO Plant Production and Protection Series, $n^{\circ}$ 30. Roma: FAO. 2002. Disponível na Internet em: www.fao.org./DOCREP/006/Y4011E/y4011e0g.htm. Acesso em 16/08/2004.

VIEDMA, L.Q. Identificación y utilización de resistencia genética durable a royas en trigo. In: Seminario Internacional Resistencia a Royas en Trigo, 2003, La Estanzuela. Seminario Internacional Resistencia a Royas en Trigo - Resumenes. La Estanzuela: INIA, 2003. p.4.

WAHL, I., ANIKSTER, Y., MANISTERSKI, J. \& SEGAL, A. Evolution at the center of origin. In: Bushnell, W.R. \& Roelfs, A.P. (Eds.) The Cereal Rusts: Origins, specificity, structure and physiology. New York: Academic Press, 1984. pp.39-72. 